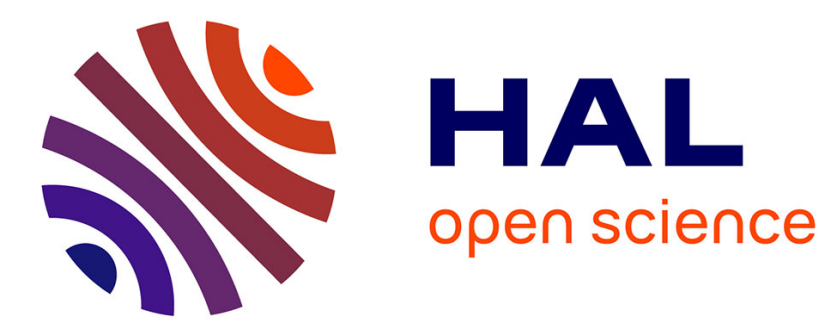

\title{
Assessing the role of slab rheology in coupled plate-mantle convection models
}

Léa Bello, Nicolas Coltice, Paul J. Tackley, R.D. Müller, John Cannon

\section{To cite this version:}

Léa Bello, Nicolas Coltice, Paul J. Tackley, R.D. Müller, John Cannon. Assessing the role of slab rheology in coupled plate-mantle convection models. Earth and Planetary Science Letters, 2015, 430, pp.191-201. 10.1016/j.epsl.2015.08.010 . hal-01355776

\section{HAL Id: hal-01355776 https://hal.science/hal-01355776}

Submitted on 24 Aug 2016

HAL is a multi-disciplinary open access archive for the deposit and dissemination of scientific research documents, whether they are published or not. The documents may come from teaching and research institutions in France or abroad, or from public or private research centers.
L'archive ouverte pluridisciplinaire HAL, est destinée au dépôt et à la diffusion de documents scientifiques de niveau recherche, publiés ou non, émanant des établissements d'enseignement et de recherche français ou étrangers, des laboratoires publics ou privés. 


\title{
Assessing the role of slab rheology in coupled plate-mantle convection models
}

\author{
Léa Bello ${ }^{a, *}$, Nicolas Coltice ${ }^{a, b}$, Paul J. Tackley ${ }^{c}$, R. Dietmar \\ Müllerd, John Cannon ${ }^{d}$ \\ ${ }^{a}$ Laboratoire de Géologie de Lyon - Terre, Planètes, Environnement, \\ U.C.B.L. - E.N.S. Lyon, - C.N.R.S., Lyon, France. \\ ${ }^{b}$ Institut Universitaire de France. \\ 'Institute of Geophysics, Department of Earth Sciences, E.T.H. Zurich, \\ Switzerland. \\ ${ }^{d}$ EarthByte Group, University of Sydney, Sydney, Australia.
}

Cite as Bello, L., Coltice, N., Tackley, P. J., R.D. Müller, J. Cannon (2015). Assessing the role of slab rheology in coupled plate-mantle convection models. Earth and Planetary Science Letters 430, 191-201.

\begin{abstract}
Reconstructing the 3D structure of the Earth's mantle has been a challenge for geodynamicists for about 40 years. Although numerical models and computational capabilities have substantially progressed, parameterizations used for modeling convection forced by plate motions are far from being Earth-like. Among the set of parameters, rheology is fundamental because it defines in a non-linear way the dynamics of slabs and plumes, and the organization of lithosphere deformation. In this study, we evaluate the role of the temperature dependence of viscosity (variations up to 6 orders of magnitude) and the importance of pseudo-plasticity on reconstructing slab evolution in 3D spherical models of convection driven by plate history models. Pseudo-plasticity, which produces plate-like behavior in convection models, allows a consistent coupling between imposed plate motions and global convection, which is not possible with temperature-dependent viscosity alone. Using test case models, we show that increasing temperature dependence of viscosity enhances vertical and lateral coherence of slabs, but leads to unrealistic slab morphologies for large viscosity contrasts. Introducing pseudo-plasticity partially solves this issue, producing thin laterally and vertically more continuous slabs, and flat subduction where trench retreat is fast. We evaluate the differences between convection reconstructions employing different viscosity laws to be very large, and similar to the differences between two models with the same rheology but using two different plate histories or initial conditions.
\end{abstract}

Keywords: mantle convection, predictability, reconstructions, rheology

\section{Introduction}

Reconstruction of the 3D structure of the

*Corresponding author: Léa Bello, Laboratoire de Géologie de Lyon, 2 rue Dubois, 69622 Villeurbanne Cedex, France Bello)
Earth's mantle was an inaccessible challenge until the end of the 1990s, when a leap forward in the quality of seismic data and computational power gave rise to tomographic models in which slabs could be detected in the lower 
mantle [Grand, 1994, van der Hilst et al., 1997]. During the same period, Bunge [1998] and Gurnis [1998] pioneered convection reconstructions from 3D convection models forced at the surface by the velocities of plate tectonic models. Thermal and seismic imaging at this time were found to be consistent, mostly imaging the large scale temperature anomalies caused by the slow sinking of slabs throughout the mantle. Today the deepest mantle remains the region of conflicting interpretations in terms of teleseismic signals and mantle tomography versus convection calculations [McNamara and Zhong, 2005, Davies et al., 2012, Bower et al., 2013].

Computing mantle convection through time requires (a) suitable initial conditions, (b) realistic material properties and (c) accurate reconstructed surface velocities. Initial conditions are fundamentally unknown and initial errors grow quickly Bello et al., 2014. Therefore several strategies to define a starting temperature field have been used, the most consistent being variational data assimilation [Bunge et al., 2003 . Ismail-Zadeh et al., 2004, Liu et al., 2008]. Realistic material properties are difficult to implement, because of numerical difficulties or uncertainties on their values, a fundamental one being rheology. Reconstructed surface velocities are produced by plate kinematic models, which inevitably loose accuracy as deeper time is concerned [Seton et al., 2012].

Among these three issues, the impact of kinematic models is the most studied. Kinematic models have been incrementally improved using geological and geophysical observations, paired with mantle convection reconstructions and seismic tomography. Comparisons between dynamic topography computed from the convection model and stratigraphic observations have been interpreted to locate sinking slabs Gurnis, 1998, Flament et al., 2014]. Similarities between tomographic models and convection models are a basis for proposing particular scenarios of slab sinking in the mantle [for instance Bunge and Grand, 2000], or in aiding improvements of the reference frame for plate reconstructions [Shephard et al., 2013.

While it is often stated as a fundamental issue to investigate [Bunge and Grand, 2000], the impact of rheology on slab reconstructions has been neglected. Hence, this manuscript focuses on the impact of the choice of rheology on reconstructing sinking slabs in the mantle. Modelling the viscosity variations in models for convection reconstruction is crucial because it drives slab shape and plume dynamics [Zhong et al., 2000]. For instance, rheological parameters used in former studies are not consistent with the velocities imposed at the surface. In studies with no or a small temperature dependence of the viscosity, the surface should be deformable and toroidal motion negligible, whereas in studies with a larger temperature dependence of the viscosity, convection should be in the stagnant lid regime [Solomatov, 1995]. In recent years, 3D spherical models of convection with plate-like behavior have been developed van Heck and Tackley, 2008, Rolf and Tackley, 2011|, producing convection models more consistent with Earth's surface tectonics Coltice et al. 2012. 2013]. These models are in principle closer to Earth's dynamic regime, with stiff mobile plates and narrow shear zones where deformation is localized.

We here evaluate the reconstructions produced by sophisticated test case models of 3D spherical convection employing a variety of rheological parameters. We show that models with plate-like behavior are the only models that can (a) be consistently scaled to exhibit a reasonable similarity to plate reconstructions and (b) produce flat subduction in regions of fast trench retreat. Differences between two models with different rheological parameters are large for the position and morphology of slabs, and similar in magnitude to those produced by alternative initial conditions or plate kinematics uncertainties.

\section{Modeling convection reconstructions}

Building a convection reconstruction model takes 3 steps: starting from a specific initial condition, imposing surface velocities from a plate reconstruction model, and solving the equations of convection. In this study, the numerical solution of convection motions is obtained using the 3D spherical convection code StagYY Tackley, 2008]. StagYY solves the conservation equations for mass, momentum and energy on a staggered Yin-Yang grid Kageyama and 
Sato, 2004], and allows for large lateral viscosity variations. The specific rationale for using StagYY is that we aim to resolve up to $10^{6}$ viscosity changes, which is 2 to 3 orders of magnitude higher than in previous convection studies [Zhong et al., 2000, Zhang et al., 2010, Bower et al., 2013, for instance]. We are then able to produce convection models with stiff slabs.

\subsection{Convection model}

We work here with dimensionless equations, and we make several approximations. First, convection is assumed to be incompressible under the Boussinesq approximation. We understand that compressibility can be an important factor, especially in the deepest mantle, but we here focus on the impact of rheology. Because of this choice, we do not take into account variable material properties (expansion coefficient, thermal diffusivity, heat production), except for the viscosity.

The Rayleigh number $R a$ in our calculations is given by:

$$
\mathrm{Ra}=\frac{\rho g \alpha \Delta T L^{3}}{\kappa \eta_{0}}
$$

where $\rho$ is density, $g$ is gravitational acceleration, $\alpha$ is thermal expansivity, $\Delta T$ is the temperature drop across the whole depth, $L$ is mantle thickness, $\kappa$ is thermal diffusivity and $\eta_{0}$ is the reference viscosity obtained at non-dimensional temperature $T=1$ at the base of the mantle. In our models, Ra is $10^{6}$, which is about 10 50 times lower than what is expected for the Earth. This choice is governed by the computational power required to solve for convection with large viscosity variations. The average resolution is $45 \mathrm{~km}$ in the 3 directions for all the models. As a consequence, we are not able to exactly reproduce Earth's structures since lower $R a$ convection produces thicker convective structures (thermal boundary layer, slabs and plumes). However, the goal here is not to predict Earth-like structures but rather to evaluate how choosing a rheological parameterization impacts the quality of reconstructions. Hence, the only parameters we vary in this study are the activation energy and the stress dependence of the viscosity. A complete summary of the parameters used in this study is in Table 1 , and typ- ical temperature and viscosity profiles are shown in Fig. 1 .

The viscosity $\eta$ in our models depends on temperature and depth as

$$
\eta_{T}(T, z)=\eta_{z}(z) \exp \left(A+\frac{E}{T}\right),
$$

where $T$ is the temperature, $z$ is the depth, $A$ is a constant that ensures the viscosity is $\eta_{z}(z)$ when $T$ is 1 , and $E$ is the non-dimensional activation energy. The depth-dependence of viscosity is taken into account such that

$$
\eta_{z}(z)=a \exp \left(\ln (B)\left[1-\frac{1}{2}\left(1-\tanh \left(\frac{d_{0}-z}{d_{\text {step }}}\right)\right)\right]\right),
$$

where $B$ stands for the factor of viscosity jump at depth $d_{0}$ over a thickness $2 d_{\text {step }}$, and $a$ is a prefactor that ensures that the reference viscosity is $\eta_{0}$ for temperature $T=1$ at the base of the mantle. Geoid Hager, 1984, Ricard et al. 1993] and post-glacial rebound studies [Mitrovica, 1996] suggest the viscosity jumps by a factor of 30 to 100 in the deep mantle. The cause of this jumps and its exact location are not known yet, but the $660 \mathrm{~km}$ seismic discontinuity is a relevant candidate. We choose here to impose a 30 -fold viscosity increase between 800 and $1000 \mathrm{~km}$, because our thermal boundary layer is 3 times thicker (about $350 \mathrm{~km}$, see Fig. 1) than on Earth. Indeed, choosing a jump at $660 \mathrm{~km}$ would make the asthenospheric upper mantle smaller than the thermal boundary layer.

The viscosity can also vary with stress in our calculations through a pseudo-plastic rheology, in a way that plate-like behavior can be modeled (see Moresi and Solomatov [1998], Trompert and Hansen [1998], Tackley [2000]). The yield stress $\sigma_{Y}$ increases linearly with total pressure as: $\sigma_{Y}(p)=\sigma_{Y}^{\text {surface }}+p * \dot{\sigma}_{Y}, \dot{\sigma}_{Y}$ being the yield stress gradient with total pressure. When the local stress reaches the yield stress, the local viscosity is given by

$$
\eta_{Y}=\frac{\sigma_{Y}(z)}{2 \dot{\varepsilon}},
$$

where $\dot{\varepsilon}$ is the second invariant of the strain rate tensor. The StagYY code has been benchmarked with such rheology [Tosi et al., 2015]. Because a low viscosity channel below the cold boundary layer has been proposed, improving 
plate-like behavior (Tackley [2000], Richards et al. [2001] and references therein), in our models the viscosity drops by a factor of 10 in the vicinity of ridges where the temperature crosses the solidus temperature $T_{s o l}$, given by a simple linear solidus model:

$$
T_{\text {sol }}(z)=0.6+7.5 z .
$$

The temperature variations in our calculations are caused by a thermal gradient from the bottom to the top, since $T=0$ at the surface and $T=1$ at the base of the mantle, and by constant internal heat production. The heat production is adjusted to obtain a basal heat flux of about $14 \%$ of the total, which is in the lower range of estimates for the heat flow at the core-mantle boundary Lay et al. [2008]. Since we focus this study on slabs, this value is not critical here.

\subsection{Imposing surface velocities}

Imposing surface velocities based on plate reconstructions on a convection model was pioneered by Bunge [1998. Since then, the method of imposing surface time-dependent boundary conditions has become the rule to produce coupled plate-mantle convection models. The simplest approach, that we follow here, is to impose velocities predicted by a plate reconstruction model for times corresponding to the calculation time. A more sophisticated approach, which also adds additional constraints to the system to enforce the geometry of slabs and boundary layer thermal structure, is to impose also thermal anomalies in the shallow upper mantle and subduction diving boards as described in Bower et al. [2013] and Flament et al. [2014]. We allow the thermal boundary layer to develop freely and the slabs to sink freely.

We use the plate reconstruction of Seton et al. [2012] for the past $200 \mathrm{My}$, and produce with the software GPlates [Boyden et al., 2011] plate stages every 0.1 My to have continuously closing polygons [Gurnis et al. 2012]. The time step in our models is always greater than $0.1 \mathrm{My}$. The local surface velocity is computed by first identifying the plate to which the location belongs using a plate-in-polygon algorithm Bevis and Chatelain, 1989], and by applying rotation information. Because convection parameters for any model cannot be exactly those of the Earth, connecting a plate reconstruction model to a convection model requires a specific adaptor. This adaptor is a scaling of time by the transit time (the time a slab would take to cross the mantle at the root-mean-square surface velocity of the model ). As a consequence the dimensional scaled time is $t_{\text {scaled }}=t \times v_{r m s}^{\text {model }} / v_{r m s}^{\text {Earth }}$, with $v_{\text {rms }}^{\text {Earth }}=3.96 \mathrm{~cm} \mathrm{y}^{-1}$.

Obtaining the value for $v_{r m s}^{\text {model }}$ is a fundamental and sometimes unappreciated problem. The major issue arises because free convection with temperature- and depth-dependent viscosity allowing $10^{2}$ to $10^{3}$ lateral viscosity variations, produces a convection mode for which the rms surface velocity is a fraction of the rms velocity in the upper mantle. When the lateral viscosity contrast is allowed to exceed $\sim 10^{4}$, the surface becomes a stagnant lid Solomatov and Moresi, 1997]. These regimes are at odds to what is observed on Earth. Hence, $v_{r m s}^{\text {model }}$ is not appropriate for the scaling for a convection mode with mobile plates at the surface. It is important to note that if the slabs are driven too fast, the surface heat flux will be too large, over cooling the mantle. If slabs are driven too slow, the surface heat flux will not be sufficient and the system can potentially heat up while it should not. If this happens in a model where the temperature dependence of viscosity is large (lateral variations of viscosity are $10^{5}$ or higher), the model degenerates because of the non-linear relationship between viscosity and temperature.

A strategy proposed is not to use any scaling, the argument being that the convection parameters in these studies are assumed to be in the range of those of the Earth [Zhang et al., 2010, Davies et al., 2012]. However, no verification can be made since the free models produce a regime of convection significantly different than the one which is targeted with imposed plate motions. A more consistent approach developed recently by Bower et al. 2013] and used in subsequent work by their group [Flament et al. 2014. Shephard et al., 2014, among others] is to impose the thermal structure of slabs in the upper mantle in order to guarantee a buoyancy flux consistent with imposed surface kinematics. Another strategy is to use the force-balance method, which ensures that the coupling be- 
tween plates and convection is not altered by driving forces at the surface. In force-balance models, the stress field is derived from the prescribed plate geometry, hence the corresponding plate-like surface velocities can be dynamically updated [for an overview, see Lowman, 2011].

Our solution is to make use of models with self-consistent generation of plate tectonics: because these models produce plate-like surface motion we can coherently compute $v_{r m s}^{\text {model }}$. To obtain plate-like behavior, lateral viscosity variations need to be large $\left(>10^{4}\right)$ and the yield stress is required to be in a specific range [Moresi and Solomatov, 1998, Tackley, 2000]. In our models, plate-like behavior is obtained for non-dimensional yield stresses between 5000 to 30000 . We choose an intermediate value of 15000 in the following. Our calculations with pseudo-plasticity produce a mobile surface in the form of very viscous stable plates bounded by localized zones of shearing in which the viscosity is low because of yielding (see Fig 2). Hence, $v_{r m s}^{\text {model }}$, which fluctuates by about $20 \%$ through time, is appropriate for a more consistent scaling for our models with lateral viscosity variations of $10^{5}$ and $10^{6}$.

In the following, we also present calculations with smaller lateral viscosity variations of $10^{2}$ and $10^{3}$ for evaluation. If we introduce pseudoplasticity in these models, surface tectonics is very different from Earth. We then used $v_{r m s}^{\text {model }}$ of the convection model with $10^{5}$ lateral viscosity variations for these models as well, which illustrates that we need to make ad hoc choices to scale the time when models do not produce plate-like behavior. For a comparison, a model with the same viscosity jump but without temperature and stress dependent viscosity produces a $v_{r m s}^{\text {model }}$ of about 1300 , which is about twice the value obtained with plate-like behavior and $10^{5}$ lateral viscosity variations ( $v_{r m s}^{\text {model }}$ being 630 and 750 for $10^{5}$ and $10^{6}$ lateral viscosity variations respectively). It is about 650 for a free convection model with $10^{2}$ lateral viscosity contrast, coincidentally close to the models with plate-like behavior.

\subsection{Initial conditions}

Starting conditions for convection reconstruction models is an extremely complicated is- sue. Plate reconstructions are more uncertain as deeper time is considered, so for convection models it becomes more difficult with increasing geological time to generate a full 3D temperature field with uncertain surface boundary conditions. The best method is to use some sort of variational data-assimilation method, which is an inverse methodology to recover initial conditions that would minimize the difference between synthetic data and "observations". Bunge et al. [2003] and Liu et al. [2008] developed variational data assimilation codes in which a present-day 3D spherical temperature field derived from a tomographic model is the data to match.

The most common method is to start from a controlled state with a priori information. The difficulty with such method is that errors in initial conditions grow with time since mantle convection is intrinsically chaotic. Hence, dynamic features could result from small a priori errors [Bello et al., 2014], leading to different deep mantle structures [McNamara and Zhong. 2005]. Although we employ this methodology here, we evaluate the potential error growth in the discussion section. We first run the convection model for several billions of years without imposing surface velocities. From this calculation, we compute a 1D temperature profile averaging solutions which are at statistically steadystate (see Fig. 1). Starting from this radial temperature model, we then impose for 1 transit time the oldest plate reconstruction $(200 \mathrm{Ma})$ to develop a thermal structure in the upper boundary layer, and obtain the initial conditions. This solution is no better than any other, except we start from a 1D thermal structure developed naturally from the convection model, hence consistent with the set of parameters we use. As for scaling with $v_{r m s}^{\text {model }}$, this was not possible in previous studies. In our models with $10^{2}$ and $10^{3}$ lateral viscosity variations, the mobility of the surface is reduced, which increases the internal temperature compared to that of models with a surface as mobile as the Earth's surface. For this reason, we employ the 1D temperature profile of our model with pseudo-plasticity and the lower lateral viscosity variations $\left(10^{5}\right)$, which is more consistent with a mobile surface. 


\section{Results}

We compare mantle reconstructions obtained in five models differing only by the dependence of their rheology on temperature and stress. We assessed the effects of the temperature dependence by varying the activation energy in the viscosity law Eq. (2), and the effects of the stress dependence by introducing pseudo-plasticity following Eq. (4). In the first three models, referred to as $A, B$ and $C$, viscosity is only temperature and depth-dependent. The viscosity contrast, i.e. the range of viscosity variations over the range of temperature, is increased from $10^{2}(\mathrm{~A})$ to $10^{5}(\mathrm{C})$. In a free convective regime, these models produce a sluggish to stagnant lid convection mode [Solomatov, 1995], in which the surface is almost immobile relative to the interior. Pseudo plasticity, which can generate a self consistent plate tectonic behavior, is introduced in models $\mathrm{D}$ and $\mathrm{E}$. The viscosity contrast is increased from $10^{5}(\mathrm{D})$ to $10^{6}(\mathrm{E})$. Common parameters for these five models are summarized table 1. The viscosity law is defined so that the value of the viscosity being 1 is maintained at the base of the mantle for $T=1$. This implies that the increase in the viscosity contrast will increase the viscosity of the cold material while keeping the viscosity of the rest constant throughout the entire set of calculations. This allows us to study the characteristics of reconstructed slabs.

\subsection{Thickness and lateral continuity of the slabs}

The viscosity of cold subducted material is enhanced when the range of viscosity variations with temperature is extended. Hence, slab stiffness increases with viscosity contrast. We first study how this stiffness shapes the slabs in models with viscosity only temperature and depth-dependent. When the viscosity contrast is limited to $10^{2}$, slabs have the shape of drops that dribble through the mantle (Fig. 3 model A). There is no continuity in the slabs along the subduction zones: the cold downwellings form juxtaposed drops aligned along the subduction zones, particularly noticeable at depth 850 and $1700 \mathrm{~km}$ under Asia (Fig. 4). Increasing the range of lateral viscosity variations makes the dribbles evolve to larger trickles or columns (model B), often continuous from the surface to the lower mantle (see Fig. 3), but remaining laterally discontinuous (Fig. 4). Long and linear sheets appear only when the viscosity contrast is extended to $10^{5}$ (model C). In this model, the thickness of the slabs is considerable, especially around the Asian and North American subduction zones with a thickness extending up to 10 degrees at $200 \mathrm{~km}$ depth $(\sim 1000 \mathrm{~km})$, and under which they form a large cold aggregate (Fig. 4).

In models with large viscosity contrasts $\left(\leq 10^{5}\right)$, introducing a pseudo plastic rheology produces thinner slabs. Indeed, in the numerical solution stresses are localized at plate boundaries, focussing the deformation in narrow zones whose thinness imposes the morphology of the downwelling. Fig. 5 shows significant differences in slab morphology between models $C$ and $D$ (exactly the same parameters as $C$ but adding pseudo-plasticity), especially when comparing the thermal structures in the South Andes subduction zone. Although thinner in the upper mantle, reconstructed slabs remain laterally continuous and planar as seen in Fig. 5 . In the upper mantle, the thickness of the slabs (300 to $380 \mathrm{~km}$ in model D and 320 to $400 \mathrm{~km}$ in model $\mathrm{E}$, see Fig. 5) is comparable to the thickness of the boundary layer $(350 \mathrm{~km}$ in these models, see Fig. 1). The lateral continuity of the slabs at $1700 \mathrm{~km}$ depth in model $\mathrm{E}$ is still better preserved than for model D (Fig. 5). The differences in slab location and thickness between the two models with pseudo-plasticity are significant in the deeper mantle.

\subsection{Vertical coherence of the slabs}

As the viscosity contrast increases, slabs become stiffer, improving vertical cohesion. In model $A$, the cold drips form clearly discontinuous downwellings, whereas in model $B$, some of the trickles are continuous throughout the whole mantle depth (Fig. 3, 1700 km). At higher viscosity contrasts, the considerable thickness of the slabs frequently prevents slab detachment, which is often produced because the trench moves away from where the downwelling previously started to sink vertically. This behavior is particularly visible in model $\mathrm{C}$, for which slabs in the North and west of the Pacific, are still attached to paleosubducted slabs (Fig. 3). 
The pseudo-plastic rheology often causes the slabs to break off before reaching the base of the mantle. The lateral coherence of the slabs is preserved as they sink into the mantle, forming long planar downwellings, but most of the slabs in model $\mathrm{D}$ and model $\mathrm{E}$, eventually detach from the surface. Progressive changes in orientation of surface velocities and migration of plate boundaries amplify the stresses applied at subduction zones, which causes a viscosity reduction in the lithosphere facilitating slab detachment.

\subsection{Location of slab hinge}

Pseudo-plastic rheology also affects the location where slabs effectively start to sink through the mantle. The reconstructed slabs in models A to $C$ dip into the mantle at the exact location of the plate boundary. However, when using a pseudo plastic rheology, the slab hinge can be distant from the boundary (Fig. 4 and 5 at 200 and $850 \mathrm{~km}$ ). A closer look at the Central and South American subduction zones shows that the slabs in models $D$ and $E$ are sinking eastward from the plate boundary (Fig. 5 at 200 and $850 \mathrm{~km}$ ). In the vertical section of the present day reconstructed temperature field beneath the South Andes (Fig. 3) the slab is flat before it starts to sink through the mantle in model $\mathrm{E}$. The same behavior is observed beneath North America, and in model D. In these two models, the location of slab hinge is far East of the trench compared to models A, B and C (Fig. 4 and Fig. 5, $200 \mathrm{~km}$ to $850 \mathrm{~km}$ ).

In this area, trench retreat is fast |Müller et al., 2008, Funiciello et al., 2008], which causes the plate boundary to move westward. When a simple temperature and depth-dependent rheology is employed, the surface velocities drag the entire stiff lithosphere and the limit between two converging plates determines the location of the slab descent. With pseudo-plasticity, high stresses caused by surface velocity gradients or slab drag generate a drop in viscosity within the plate boundary region. The low viscosity regions produce shear zones that can decouple slab motion from surface motion as seen in Fig. 6. Hence, the imposed surface velocities do not necessarily impose the location of the sinking of the slab. The combination of fast trench motion and a low viscosity channel is known to produce the flat subduction pattern, as in Manea and Gurnis [2007]. When trench retreat is too fast, the sinking slab detaches and new subduction starts closer to the plate boundary.

\subsection{Upwellings and small scale convection}

Small scale convection is present in the uppermost part of the mantle, particularly in the models with low temperature dependence of viscosity. At the base of the lithosphere of models $A$ and $B$, the lateral temperature variations due to secondary convection form a network of very sharp and thin cold thermal structures (Fig. 4 at $200 \mathrm{~km}$ ). Increasing the viscosity contrast leads to stiffer, thicker and more stable lithosphere, which only destabilizes far from the spreading ridges, long after its formation. Small scale convection exists beneath the western Pacific even for high viscosity contrasts (Fig. 4).

Hot plumes coming from the base have a similar size in the five models but display a variety of distributions while rising through the mantle. Rising hot material forms long linear sheets at the base of the mantle, surrounded by cold material (Fig. 4 and 5), and breaking into plume-like structures as they leave the core-mantle boundary. The cold downwellings, located beneath the subduction zones, control the location of rising hot material, leading to a similar distribution in the lower mantle for the five models: warm upwellings gather underneath central Atlantic, Africa and below the central Pacific. The spreading of downwellings at the base of the models differs when varying the rheology: when the viscosity contrast is stronger, hotter regions are more concentrated beneath the Pacific and eventually Africa (Fig. 4 and 5). But overall, the very large-scale structure is consistent between models.

\section{Discussion}

Understanding the role of rheology in driving the morphology of the convective structures is crucial, as it is a key ingredient for convection modeling. We have investigated the effects of temperature dependence of viscosity and pseudo-plasticity by making a comparative study of thermal fields produced through test case 
models featuring a pseudo-plastic and/or depth and temperature-dependent rheology, and imposed surface velocities taken from Seton et al. [2012]. The models presented here have a lower convection vigor than Earth, the Rayleigh number being lower by a factor of 10-50, and other parameters are simplified (no compressibility, no material properties computed as a function of mineralogical assemblage, no free surface, no continental lithosphere). Hence, it is not our goal to use them as realistic reconstructions of convection for the Earth mostly because the boundary layer is thicker that expected for the Earth, being $300 \mathrm{~km}$ to $350 \mathrm{~km}$ in our models.

\subsection{Pseudo-plasticity with strong temperature- dependence viscosity improves convection reconstructions}

Although our models are test case models, they show how slab morphology is dependent on rheological parameters. Models employing a rheology that is only depth- and temperaturedependent are not able to generate long and planar downwellings for a viscosity contrast lower than $10^{5}$. These models favor downwellings that form soft drips. For a viscosity contrast of $10^{5}$, the thickness of the slabs is excessive, especially close to the trench. For these reasons, Bower et al. 2013 have developed a strategy to impose slab thermal structure to ensure coherent slabs sinking in the lower mantle. Continuous structures could be produced artificially by driving the surface velocities at a very high pace, but it would cool the model at an unphysical fast rate.

Employing pseudo-plasticity with enhanced temperature dependence of viscosity makes a fundamental difference. First, because such rheology naturally produces a plate-like behavior, imposing properly scaled plate velocities as boundary conditions on the convection model becomes possible. When models with temperature dependent viscosity alone are used, there is no direct way to ensure that imposed scaled plate velocities are too fast or too slow, leading to unnatural convective structures. This difficulty has been partly overcome in prior models by Bower et al. 2013] for instance, who impose at each step a thermal structure of the slabs in the first $350 \mathrm{~km}$ to obtain buoyancy fluxes consistent with plate kinematics. Such effort is necessary when pseudo-plasticity is not used. The trade-off of this method is that the thermal structure is more imposed than naturally arising, as it can be with convection models with pseudo-plasticity.

Using pseudo-plasticity leads also to thinner slabs close to the trench, and laterally and vertically more continuous, but with a tendency to detach. These results are consistent with those reported from regional modelling: strong temperature dependence of the viscosity and yielding produce the range of subduction evolutions observed on Earth Billen and Hirth. 2007, Čižková et al., 2002. Ignoring yielding in regional models prevents lateral variation of viscosity within the slab, hence stresses are transmitted in a different manner. In this case, weaker plates are required Stegman et al., 2010]. But such rheology would not generate plate-like behavior in a global framework.

In our models, visco-plasticity allows shearing over short distances, producing flat subduction in regions of rapid trench retreat like in the Andes, where flat subduction is locally observed [Fukao et al., 2001, Fukao and Obayashi, 2013. Such behavior is similar to that of models of subduction with fast trench motion and a low viscosity zone close to the surface Manea and Gurnis, 2007]. It suggests that fast motion of the overriding plate is a major factor for flat subduction as proposed previously by Cross and Pilger [1982]. Although, modelling flat subduction on Earth may require additional physics. Indeed, our test case models do not produce flat slabs at the expected location on Earth, like in under North America where it has been identified in seismic tomography and reconstructed in convection models imposing a specific geometry of subduction Bunge and Grand, 2000, Liu et al., 2008). Even our most sophisticated model (model E) does not produce slabs lying above the more viscous lower mantle as it is the case in regional tomographic models [ $L i$ and van der Hilst, 2010, Fukao and Obayashi, 2013]. Increasing convection vigor and improving the description of variable material properties would likely improve this behaviour. Particularly, including phase changes has been demonstrated to favor the development of stagnant slabs Chris- 
tensen and Yuen, 1984, Tackley et al., 1993], even in 3D spherical convection models featuring temperature dependent viscosity and plastic yielding [Yanagisawa et al., 2010]. Also, a continuous model of surface kinematics Bercovici and Wessel, 1994 would be more consistent with our numerical models than the discontinuous plate kinematics, and may impede slab detachment. As a matter of fact, imposing plate models results in higher stresses and more localized shear zones than occurs naturally in free convection with plate-like behavior using our parameters.

\subsection{Errors caused by uncertainties in rheology, initial conditions and plate history}

The extreme variability in slab thickness, stiffness, lateral and vertical continuity, and location of dip when rheological parameters are varied implies that uncertainties in convection models are large. To quantitatively evaluate this issue, we computed the global average error on the temperature field between model $\mathrm{C}$ and model D following the method of Bello et al. [2014]. We monitor the value of this error $E(t)$ through time:

$$
E(t)=\int_{V_{\Omega}} \frac{\left|T_{p}(\mathbf{x}, t)-T(\mathbf{x}, t)\right|}{T(\mathbf{x}, t)} \frac{d V(\mathbf{x})}{V_{\Omega}}(6)
$$

where $T(\mathbf{x}, t)$ and $T_{p}(\mathbf{x}, t)$ represent the temperature at position $\mathbf{x}$ and time $t$ of the reference twin and the perturbed twin, respectively. $V_{\Omega}$ is the volume of the model in which the temperature is not imposed by boundary conditions.

Because uncertainties in convection reconstructions also originate from initial conditions, we compute a convection reconstruction identical to model $D$ but we add to the initial temperature field (at the time the reconstruction starts) a random error of magnitude $\pm 5 \%$ of the local temperature as in Bello et al. [2014]. To assess the errors introduced by uncertainties in plate kinematics, we also compute a model differing from model $D$ only by using imposed surface velocities taken from Shephard et al. [2013] instead of Seton et al. [2012]. The resulting errors are summarized in Fig 7 .

Although structures seem to look alike to the eye, the global error between models with and without pseudo-plasticity is very large here, since it reaches values similar in magnitude to the maximum global error between two uncorrelated states of a convection model [Bello et al., 2014]. As discussed before, the location, thickness and continuity of the downwellings are significantly different. This error is close to that produced using two distinct but recent models of plate kinematics. The kinematic model of Shephard et al. [2013] introduces improvements in the Arctic region compared to that of Seton et al. [2012]. Shephard et al. [2014] provide a more detailed study of these differences and consequences in mantle flow too. Other authors have already made such analysis of the impact of uncertainties in plate kinematics on convection reconstructions and we refer to their work Zhong et al., 2000, Bunge and Grand, 2000, Butterworth et al., 2014]. As stated by McNamara and Zhong |2005], uncertainties in initial conditions modify the global structure of the flow. The error produced by perturbing our initial conditions decreases in the first 10 My because of thermal diffusion of the smaller scale errors, and then grows by more than a factor of 3 . We expect that errors in initial conditions, certainly being no smaller than $5 \%$ for the large-scale flow, will then reach $10 \%$ before the end of the calculation. Hence, uncertainties in initial conditions produce errors similar to those obtained by uncertainties in plate kinematics and rheology.

\section{Conclusions}

Using test case geodynamic models, namely convection models not designed for direct interpretation of 3D mantle structure but for a comparative analysis, we have shown that the temperature and stress dependence of the viscosity is crucial to model the morphology of slabs. This is consistent with regional subduction models |Billen and Hirth, 2007, Čižková et al. 2002. The choice of rheology dictates slab lateral and vertical continuity, and the way it sinks. Therefore, large differences are observed in the reconstructed thermal fields between models with small and large viscosity variations caused by temperature and stress. Such differences are comparable in magnitude to the global error produced by changing the plate reconstruction model or initial conditions. 
Using pseudo-plasticity in convection models is a leap forward for convection models, because it allows a consistent scaling of surface motions and initial boundary layer thicknesses. In addition, pseudo-plasticity can produce flat slabs when trench retreat is fast. However, even our most advanced model leads to a somewhat unsatisfactory slab geometry, since stagnant slabs in the mantle transition zone are not yet observed, or slab detachment potentially occurs too often.

Nevertheless, previous reconstructions have shown reasonable agreement with global tomographic images of the mantle Bunge and Grand, 2000, McNamara and Zhong, 2005, Shephard et al. 2014]. Because of the sparse distribution of seismic sources and receivers along with damping in the inverse methodologies, tomographic images represent a filtered view of actual mantle structures. Hence, we expect a tomographic filtering of our reconstructions to attenuate the discrepancies between the models. Particularly, small scale structures, as small scale convection under old lithosphere and thin upwellings at the base of the mantle, will not be visible [Bull et al., 2009]. We expect the poor lateral and vertical continuity of the downwellings we described in models with low viscosity contrast to be smoothed, leading to an artificial coherence even for less coherent slabs. Hence, refining the structure of sinking slabs with denser seismic networks or/and waveform modelling may provide datasets that could distinguish between parameterizations of mantle convection reconstructions.

\section{Acknowledgement}

We are thankful to the editor and both reviewers for their comments and questions, which greatly contributed to the improvement of the manuscript. The research leading to these results has received funding from Institut Universitaire de France, ENS de Lyon, and the European Research Council within the framework of the SP2-Ideas Program ERC-2013-CoG, under ERC Grant agreement number 617588. Calculations were performed on the LGLTPE Augury high-performance computing cluster, and using HPC resources from GENCI-IDRIS (grant 2014-
047243). R. Dietmar Müller was supported by Australian Research Council grant DP0987713 and John Cannon by AuScope National Collaborative Research Infrastructure funding.

\section{References}

\section{References}

Bello, L., N. Coltice, T. Rolf, and P. J. Tackley (2014), On the predictability limit of convection models of the Earth's mantle, Geochemistry, Geophys. Geosystems, 15, 2319-2328, doi:10.1002/2014GC005254.

Bercovici, D., and P. I. P. P. I. Wessel (1994), A continuous kinematic model of plate-tectonic motions, Geophys. J. Int., 119, 595-610, doi:10.1111/j.1365-246X. 1994.tb00144.x.

Bevis, M., and J.-L. Chatelain (1989), Locating a point on a spherical surface relative to a spherical polygon of arbitrary shape, Math. Geol., 21, 811-828.

Billen, M. I., and G. Hirth (2007), Rheologic controls on slab dynamics, Geochemistry, Geophys. Geosystems, 8(8), doi:10.1029/2007GC001597.

Bower, D. J., M. Gurnis, and M. Seton (2013), Lower mantle structure from paleogeographically constrained dynamic Earth models, Geochemistry, Geophys. Geosystems, 14, 44-63, doi:10.1029/2012GC004267.

Boyden, J., R. Müller, M. Gurnis, T. H. Torsvik, J. A. Clark, M. Turner, H. Ivey-Law, R. J. Watson, and J. S. Cannon (2011), Next-generation plate tectonic reconstructions using Gplates, in Model. Softw. community codes, pp. 95-113.

Bull, A., A. McNamara, and J. Ritsema (2009), Synthetic tomography of plume clusters and thermochemical piles, Earth Planet. Sci. Lett., 278, 152-162, doi: 10.1016/j.epsl.2008.11.018.

Bunge, H.-P. (1998), Time Scales and Heterogeneous Structure in Geodynamic Earth Models, Science, 280, 91-95, doi:10.1126/science.280.5360.91.

Bunge, H. H.-p., and S. S. P. Grand (2000), Mesozoic plate-motion history below the northeast Pacific Ocean from seismic images of the subducted Farallon slab, Nature, 405, 337-40, doi:10.1038/35012586.

Bunge, H.-P., C. R. Hagelberg, and B. J. Travis (2003), Mantle circulation models with variational data assimilation: inferring past mantle flow and structure from plate motion histories and seismic tomography, Geophys. J. Int., 152, 280-301, doi:10.1046/j.1365-246X. 2003.01823.x.

Butterworth, N., a.S. Talsma, R. Müller, M. Seton, H.P. Bunge, B. Schuberth, G. Shephard, and C. Heine (2014), Geological, tomographic, kinematic and geodynamic constraints on the dynamics of sinking slabs, J. Geodyn., 73, 1-13, doi:10.1016/j.jog.2013.10.006.

Christensen, U. R., and D. a. Yuen (1984), The interaction of a subducting lithospheric slab with a chemical or phase boundary, doi:10.1029/JB089iB06p04389.

Coltice, N., T. Rolf, P. J. Tackley, and S. Labrosse (2012), Dynamic causes of the relation between area and age of the ocean floor., Science, 336, 335-8, doi: $10.1126 /$ science. 1219120 . 
Coltice, N., M. Seton, T. Rolf, R. Müller, and P. Tackley (2013), Convergence of tectonic reconstructions and mantle convection models for significant fluctuations in seafloor spreading, Earth Planet. Sci. Lett., 383, 92-100, doi:10.1016/j.epsl.2013.09.032.

Cross, T. A., and R. H. Pilger (1982), Controls of subduction geometry, location of magmatic arcs, and tectonics of arc and back-arc regions, Geol. Soc. Am. Bull., 93, 545-562, doi:10.1130/0016-7606(1982)93〈545: COSGLO $>2.0 . \mathrm{CO} ; 2$.

Čižková, H., J. van Hunen, A. P. van den Berg, and N. J. Vlaar (2002), The influence of rheological weakening and yield stress on the interaction of slabs with the 670 km discontinuity, Earth Planet. Sci. Lett., 199(3-4), 447-457, doi:10.1016/S0012-821X(02)00586-1.

Davies, D. R., S. Goes, J. Davies, B. Schuberth, H.-P. Bunge, and J. Ritsema (2012), Reconciling dynamic and seismic models of Earth's lower mantle: The dominant role of thermal heterogeneity, Earth Planet. Sci. Lett., 353-354, 253-269, doi:10.1016/j.epsl.2012.08. 016.

Flament, N., M. Gurnis, S. Williams, M. Seton, J. Skogseid, C. Heine, R. Dietmar, and R. Dietmar Müller (2014), Topographic asymmetry of the South Atlantic from global models of mantle flow and lithospheric stretching, Earth Planet. Sci. Lett., 387, 107-119, doi: 10.1016/j.epsl.2013.11.017.

Fukao, Y., S. Widiyantoro, and M. Obayashi (2001), Stagnant slabs in the upper and lower mantle transition region, Rev. Geophys., 39, 291, doi:10.1029/ 1999RG000068.

Fukao, Y., and M. Obayashi (2013), Subducted slabs stagnant above, penetrating through, and trapped below the $660 \mathrm{~km}$ discontinuity, J. Geophys. Res. Solid Earth, 118, 5920-5938, doi:10.1002/2013JB010466.

Funiciello, F., C. Faccenna, a. Heuret, S. Lallemand, E. Di Giuseppe, and T. Becker (2008), Trench migration, net rotation and slab-mantle coupling, Earth Planet. Sci. Lett., 271, 233-240, doi:10.1016/j.epsl. 2008.04.006.

Grand, S. P. (1994), Mantle shear structure beneath the Americas and surrounding oceans, J. Geophys. Res., 99, 11,591, doi:10.1029/94JB00042.

Gurnis, M. (1998), Cretaceous Vertical Motion of Australia and the AustralianAntarctic Discordance, Science, 279(5356), 1499-1504, doi:10.1126/science. 279.5356 .1499

Gurnis, M., et al. (2012), Plate tectonic reconstructions with continuously closing plates, Comput. Geosci., 38, 35-42, doi:10.1016/j.cageo.2011.04.014.

Hager, B. H. (1984), Subducted slabs and the geoid: Constraints on mantle rheology and flow, J. Geophys. Res., 89(B7), 6003, doi:10.1029/JB089iB07p06003.

Ismail-Zadeh, A., G. Schubert, I. Tsepelev, and A. Korotkii (2004), Inverse problem of thermal convection: numerical approach and application to mantle plume restoration, Phys. Earth Planet. Inter., 145(1-4), 99114, doi:10.1016/j.pepi.2004.03.006

Kageyama, A., and T. Sato (2004), "Yin-Yang grid": An overset grid in spherical geometry, Geochemistry, Geophys. Geosystems, 5, doi:10.1029/2004GC000734.

Lay, T., J. Hernlund, and B. A. Buffett (2008), Core- mantle boundary heat flow, Nat. Geosci., 1(1), 25-32, doi:10.1038/ngeo.2007.44.

Li, C., and R. D. van der Hilst (2010), Structure of the upper mantle and transition zone beneath Southeast Asia from travel time tomography, J. Geophys. Res., 115, B07308, doi:10.1029/2009JB006882.

Liu, L., S. Spasojevic, and M. Gurnis (2008), Reconstructing Farallon plate subduction beneath North America back to the Late Cretaceous., Science, 322, 934-8, doi:10.1126/science.1162921.

Lowman, J. P. (2011), Mantle convection models featuring plate tectonic behavior: An overview of methods and progress, Tectonophysics, 510(1-2), 1-16, doi: 10.1016/j.tecto.2011.04.015.

Manea, V., and M. Gurnis (2007), Subduction zone evolution and low viscosity wedges and channels, Earth Planet. Sci. Lett., 264, 22-45, doi:10.1016/j.epsl. 2007.08.030.

McNamara, A. K., and S. Zhong (2005), Thermochemical structures beneath Africa and the Pacific Ocean., Nature, 437, 1136-9, doi:10.1038/nature04066.

Mitrovica, J. X. (1996), Haskell [1935] revisited, J. Geophys. Res., 101, 555, doi:10.1029/95JB03208.

Moresi, L., and V. Solomatov (1998), Mantle convection with a brittle lithosphere: thoughts on the global tectonic styles of the Earth and Venus, Geophys. J. Int., 133, 669-682, doi:10.1046/j.1365-246X.1998.00521. $\mathrm{x}$

Müller, R. D., M. Sdrolias, C. Gaina, and W. R. Roest (2008), Age, spreading rates, and spreading asymmetry of the world's ocean crust, Geochemistry, Geophys. Geosystems, 9, doi:10.1029/2007GC001743.

Ricard, Y., M. Richards, C. Lithgow-Bertelloni, and Y. Le Stunff (1993), A geodynamic model of mantle density heterogeneity, J. Geophys. Res., 98, 21895, doi:10. 1029/93JB02216.

Richards, M. A., W.-S. Yang, J. R. Baumgardner, and H.-P. Bunge (2001), Role of a low-viscosity zone in stabilizing plate tectonics: Implications for comparative terrestrial planetology, Geochemistry, Geophys. Geosystems, 2, doi:10.1029/2000GC000115.

Rolf, T., and P. J. Tackley (2011), Focussing of stress by continents in $3 \mathrm{D}$ spherical mantle convection with self-consistent plate tectonics, Geophys. Res. Lett., 38, L18301, doi:10.1029/2011GL048677.

Seton, M., et al. (2012), Global continental and ocean basin reconstructions since $200 \mathrm{Ma}$, Earth-Science Rev., 113, 212-270, doi:10.1016/j.earscirev.2012.03. 002.

Shephard, G. E., R. D. Müller, and M. Seton (2013), The tectonic evolution of the Arctic since Pangea breakup: Integrating constraints from surface geology and geophysics with mantle structure, Earth-Science Rev., 124, 148-183, doi:10.1016/j.earscirev.2013.05.012.

Shephard, G. E., N. Flament, S. Williams, M. Seton, M. Gurnis, and R. D. Müller (2014), CircumArctic mantle structure and long-wavelength topography since the Jurassic, J. Geophys. Res. Solid Earth, doi:10.1002/2014JB011078.

Solomatov, V. S. (1995), Scaling of temperature- and stress-dependent viscosity convection, Phys. Fluids, 7 , 266, doi:10.1063/1.868624. 
Solomatov, V., and L. Moresi (1997), Three regimes of mantle convection with non-Newtonian viscosity and stagnant lid convection on the terrestrial planets, Geophys. Res. Lett., 24(15), 1907-1910.

Stegman, D. R., R. Farrington, F. a. Capitanio, and W. P. Schellart (2010), A regime diagram for subduction styles from 3-D numerical models of free subduction, Tectonophysics, 483(1-2), 29-45, doi: 10.1016/j.tecto.2009.08.041.

Tackley, P. J. (2000), Self-consistent generation of tectonic plates in time-dependent, three-dimensional mantle convection simulations: 1 . Pseudoplastic yielding, Geochemistry, Geophys. Geosystems, doi:10. 1029/2000GC000036.

Tackley, P. J. (2008), Modelling compressible mantle convection with large viscosity contrasts in a threedimensional spherical shell using the yin-yang grid, Phys. Earth Planet. Inter., 171, 7-18, doi:10.1016/ j.pepi.2008.08.005.

Tackley, P. J., D. J. Stevenson, G. A. Glatzmaier, and G. Schubert (1993), Effects of an endothermic phase transition at $670 \mathrm{~km}$ depth in a spherical model of convection in the Earth's mantle, Nature, 361, 699704, doi:10.1038/361699a0.

Tosi, N., et al. (2015), A community benchmark for viscoplastic thermal convection in a 2-D square box, Geochemistry, Geophys. Geosystems, doi:10.1002/ 2015GC005807.

Trompert, R., and U. Hansen (1998), Mantle convection simulations with rheologies that generate platelike behaviour, Nature, 395(October), 686-689, doi: $10.1038 / 27185$.

van der Hilst, R. D., S. Widiyantoro, and E. R. Engdahl (1997), Evidence for deep mantle circulation from global tomography, Nature, 386, 578-584, doi: 10.1038/386578a0.

van Heck, H. J., and P. J. Tackley (2008), Planforms of self-consistently generated plates in 3D spherical geometry, Geophys. Res. Lett., 35, L19312, doi:10. 1029/2008GL035190.

Yanagisawa, T., Y. Yamagishi, Y. Hamano, and D. R. Stegman (2010), Mechanism for generating stagnant slabs in 3-D spherical mantle convection models at Earth-like conditions, Phys. Earth Planet. Inter., 183(1-2), 341-352, doi:10.1016/j.pepi.2010.02.005.

Zhang, N., S. Zhong, W. Leng, and Z.-X. Li (2010), A model for the evolution of the Earth's mantle structure since the Early Paleozoic, J. Geophys. Res., 115, B06401, doi:10.1029/2009JB006896.

Zhong, S., M. T. Zuber, L. Moresi, and M. Gurnis (2000), Role of temperature-dependent viscosity and surface plates in spherical shell models of mantle convection, J. Geophys. Res., 105, 11063, doi:10.1029/ 2000JB900003. 
Table 1: Non-dimensional convection parameters used in this study.

\begin{tabular}{|c|l|r|}
\hline Symbols & Definition & Value $^{a}$ \\
\hline $\mathrm{Ra}$ & Rayleigh number & $10^{6}$ \\
$\mathrm{~L}$ & Mantle thickness & 1 \\
$d_{0}$ & Depth of viscosity jump & 0.276 \\
$\mathrm{~B}$ & Factor of viscosity increase & 30 \\
$d_{s t e p}$ & Half thickness of viscosity jump & 0.02 \\
$\Delta T$ & Temperature drop across the mantle & 1 \\
$\mathrm{Ts}$ & Surface temperature & 0 \\
$\mathrm{H}$ & Internal heating rate & 32 \\
$E$ & Activation energy & $9-30$ \\
$\sigma_{Y}$ & Surface yield stress & $1.5 \times 10^{4}$ \\
$\sigma_{Y}$ & Yield stress gradient with total pressure & 0.025 \\
\hline
\end{tabular}

${ }^{a}$ Non dimensional. 


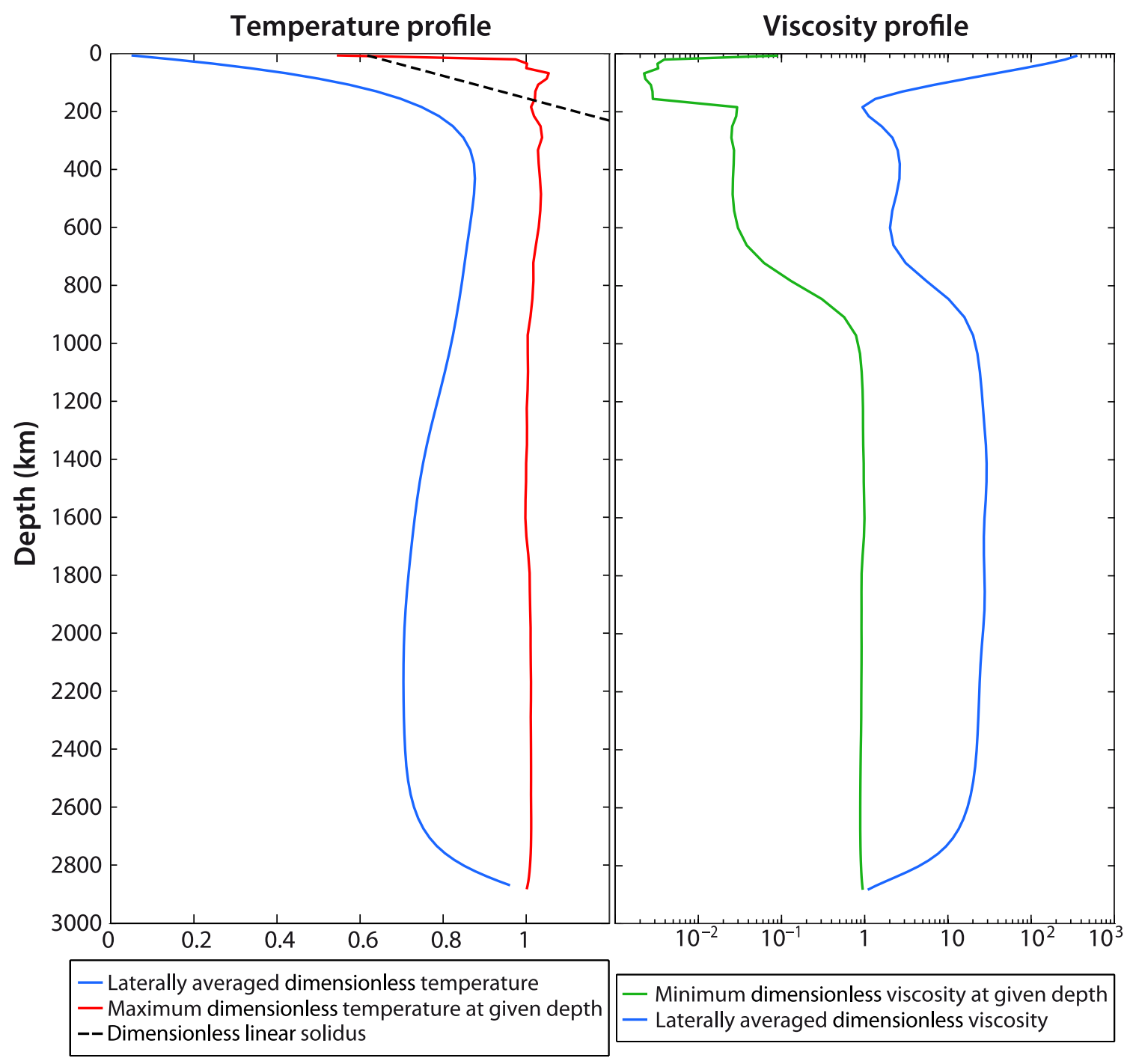

Figure 1: Non dimensional temperature and viscosity profiles computed at statistical steady state for a numerical solution of convection without imposed plate motions (free convection solution presented Figure 2). The viscosity contrast caused by temperature alone is $10^{6}$, and we use pseudo-plasticity. The choice of the parameterization is discussed in subsection 2.1. 

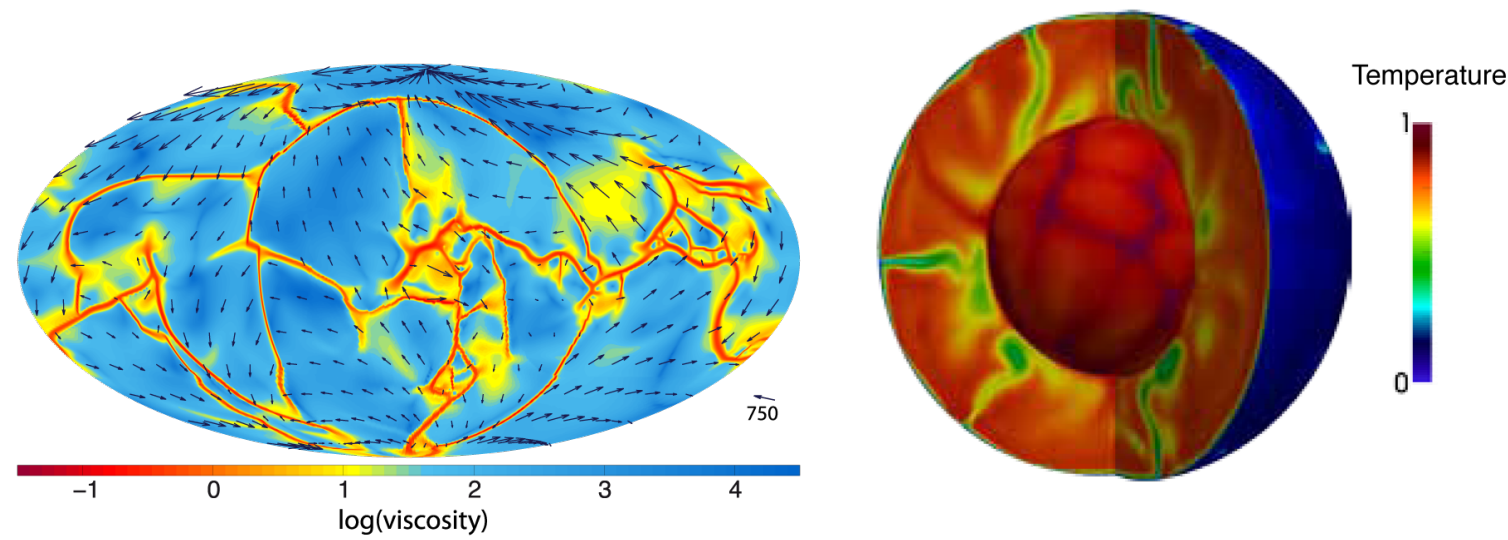

Figure 2: Snapshot of a free convection solution (no imposed plate motion) featuring pseudo-plastic rheology corresponding to parameterization of model E. (left) Viscosity and velocity fields at the surface, non dimensional. (right) Snapshot of 3D temperature field, non dimensional. 


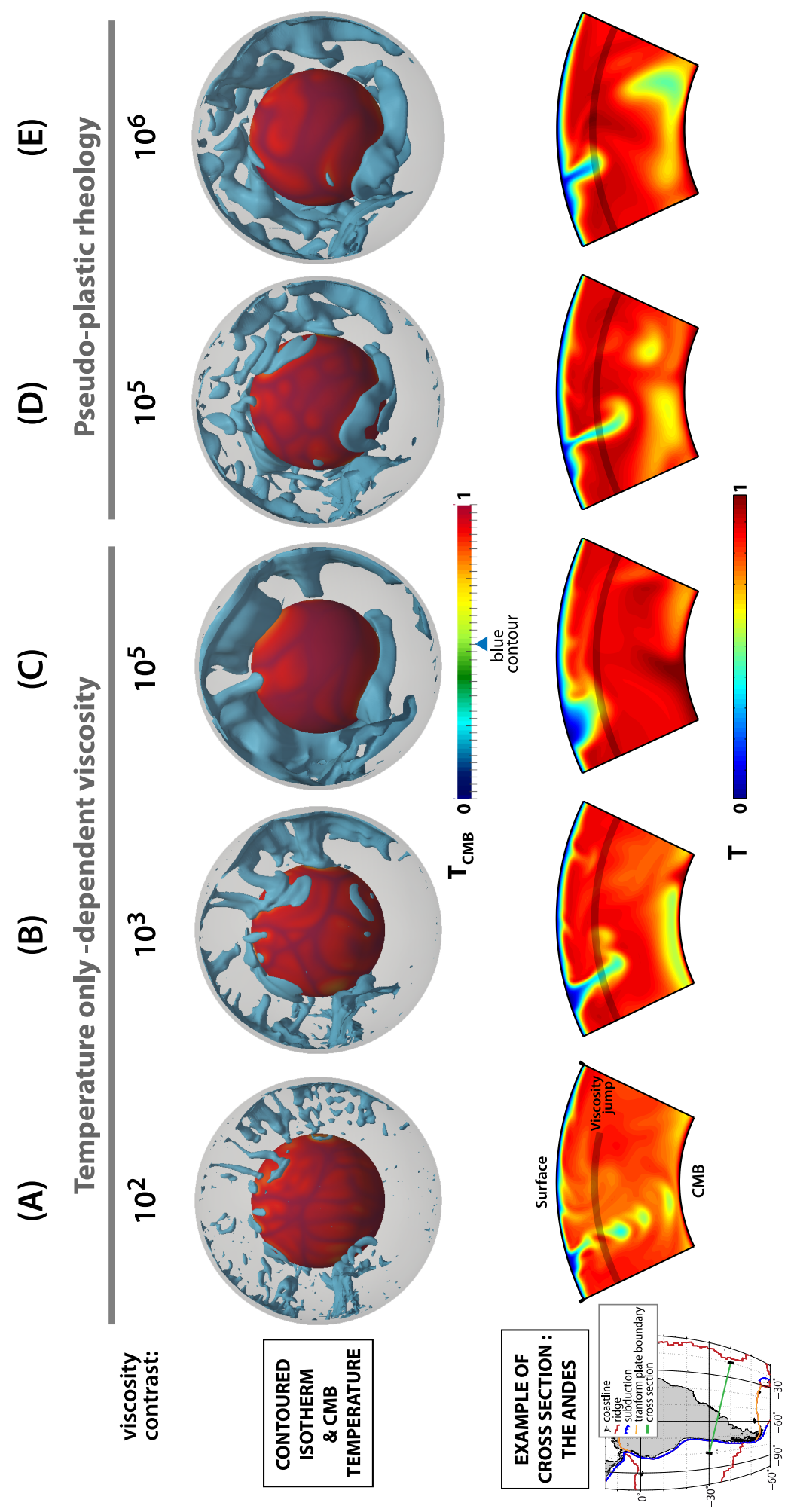

Figure 3: 3D view of the contour of the cold isotherm $T=0.55$ between the base of the lithosphere and core-mantle boundary, as seen through the Pacific, North up, in the reconstructed temperature fields for present day (see text) of five models featuring the following rheologies: (A) temperature and depth dependent viscosity with a maximum $10^{2}$ viscosity variations with temperature, $(B)$ same as $(A)$ with a maximum $10^{3}$ viscosity variations with temperature, (C) same as (A) with a maximum $10^{5}$ viscosity variations with temperature, (D) temperature and depth dependent viscosity and pseudo-plasticity with a maximum $10^{5}$ viscosity variations with temperature, (E) same as (D) with a maximum $10^{6}$ viscosity variations with temperature. A cross section beneath South America (location shown on the left) of these reconstructed temperature fields is presented for the five model. Temperature is non-dimensional. 
(A)
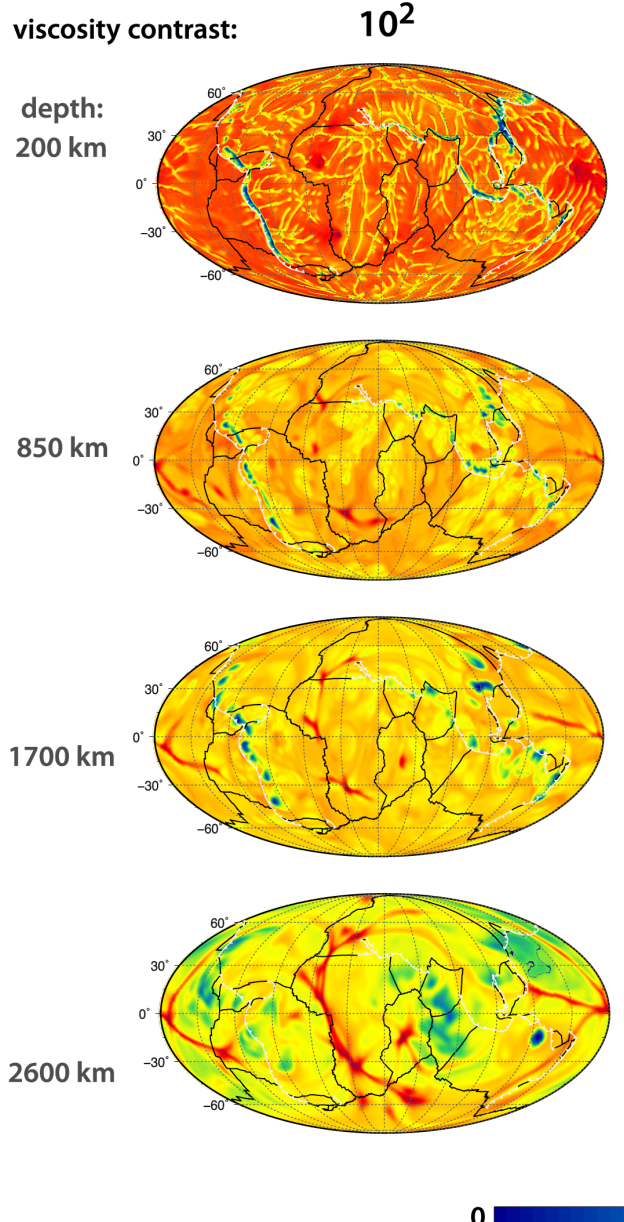

(B)

Temperature only -dependent viscosity

$10^{3}$
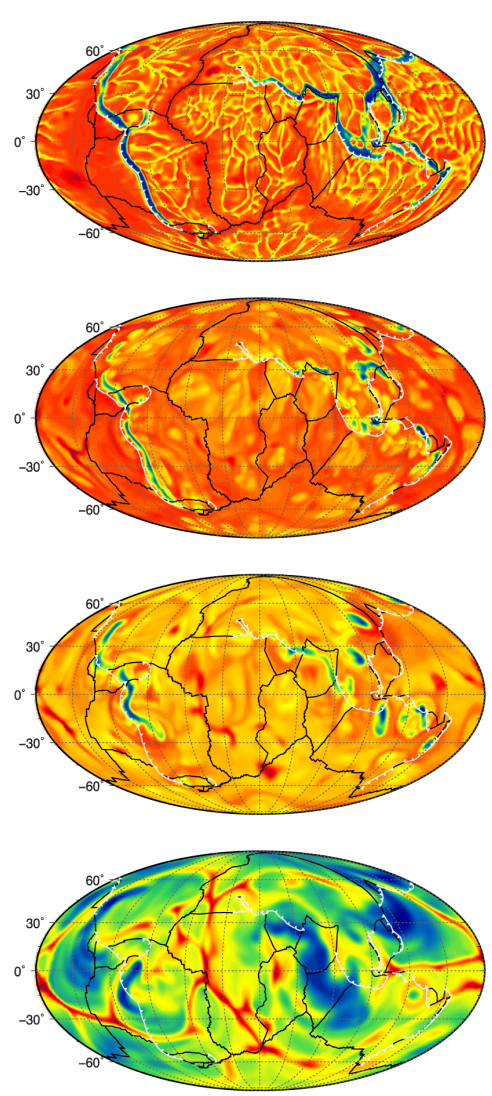

Temperature

(non dimensional)
(C)

$10^{5}$
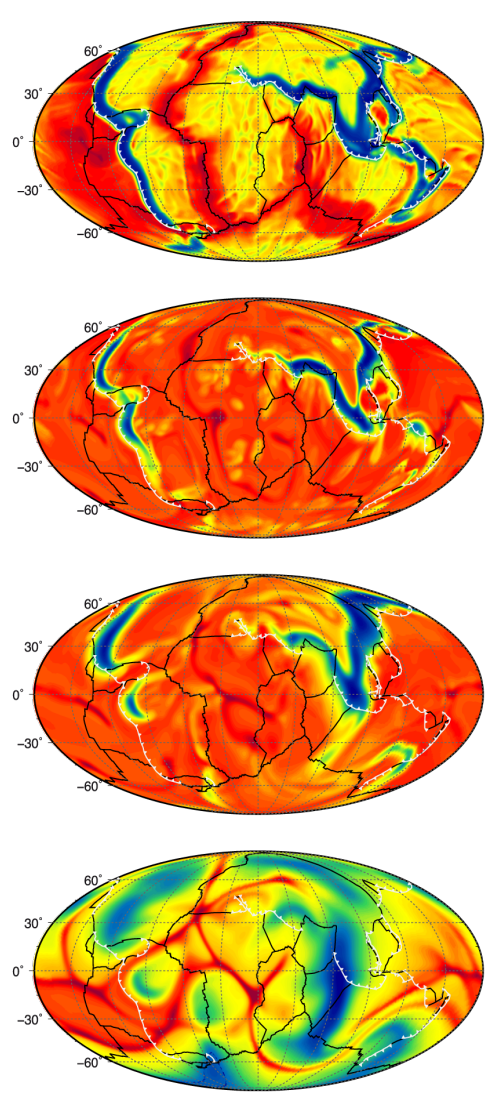

Projection of surface

$\checkmark$ plate boundaries

subduction zones

Figure 4: Computed temperature distributions at selected depth for the convection models described in Fig 3 at time present day. The viscosity contrast across the upper boundary layer increases from model A to model C. 
(C)

Temperature only -dependent viscosity

viscosity contrast:
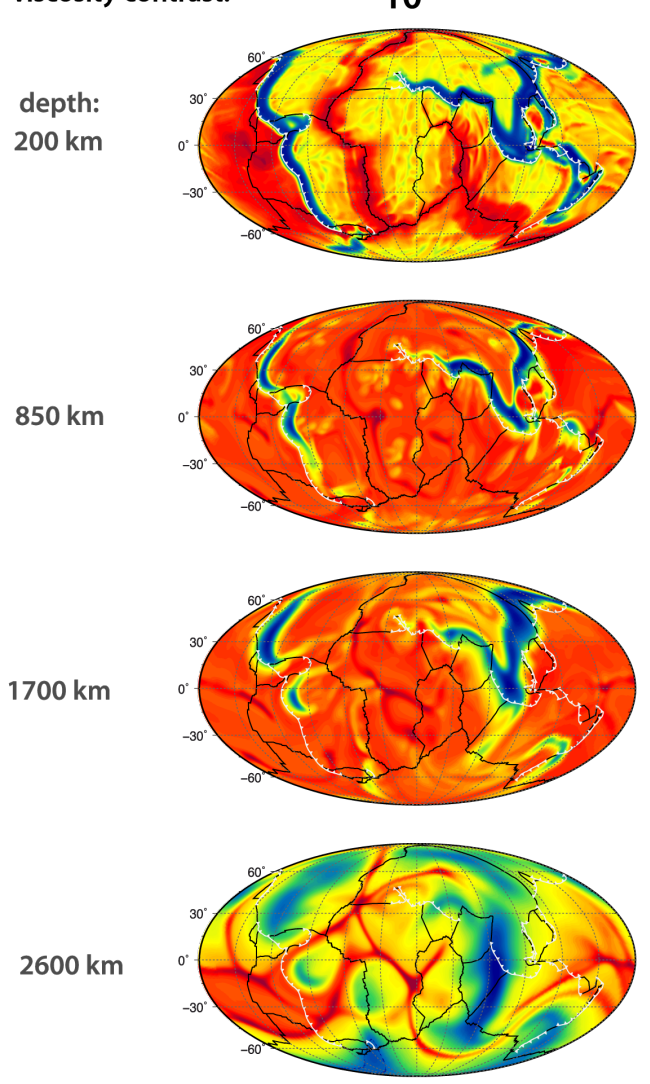

(D)

(E)
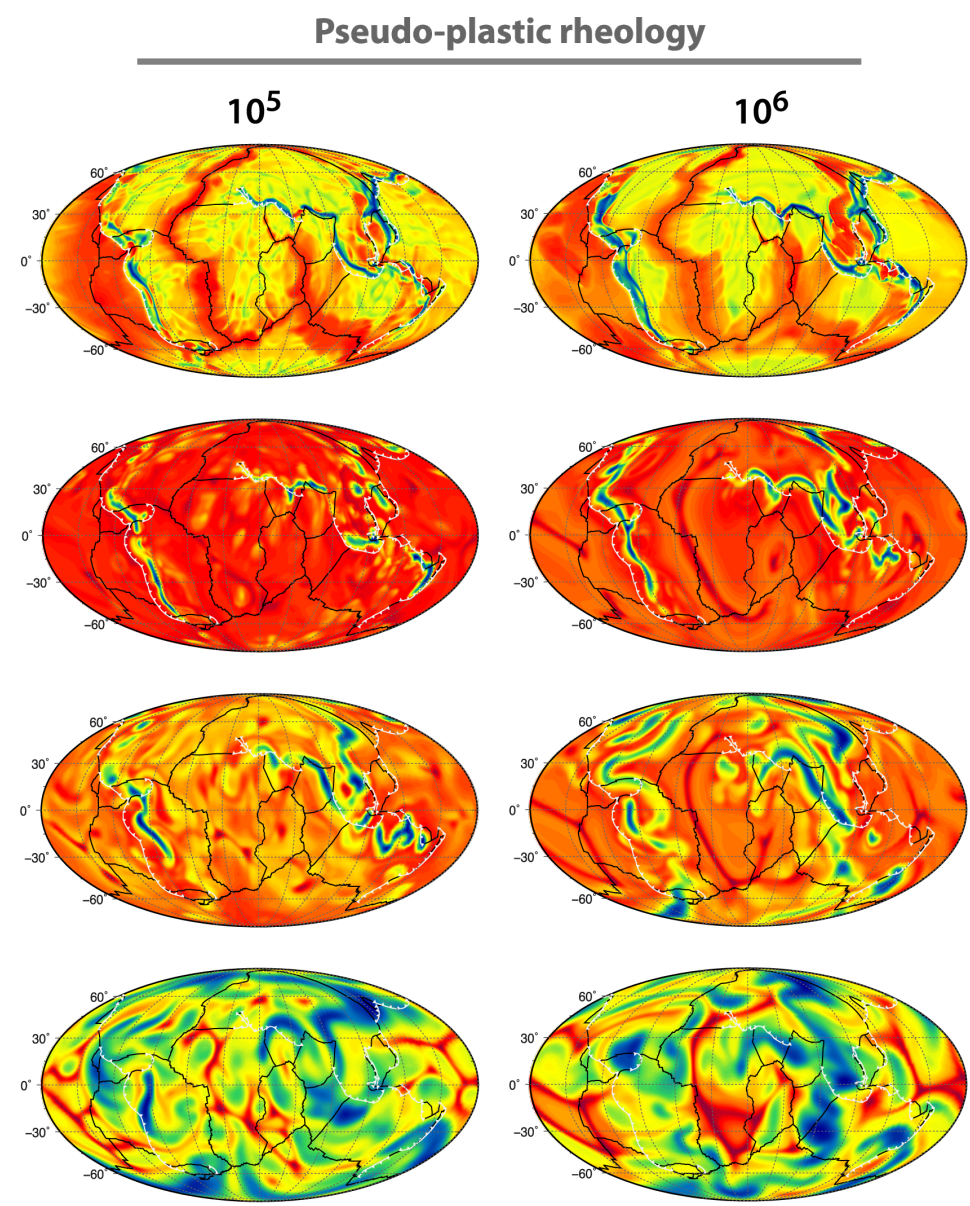

Projection of surface

7 plate boundaries

subduction zones

Figure 5: Computed temperature distributions at selected depth for the convection models described in Fig 3 at time $0 \mathrm{Ma}$. Model $\mathrm{D}$ and $\mathrm{E}$ have pseudo-plasticity, model $\mathrm{E}$ having the highest viscosity contrast among all the models. 


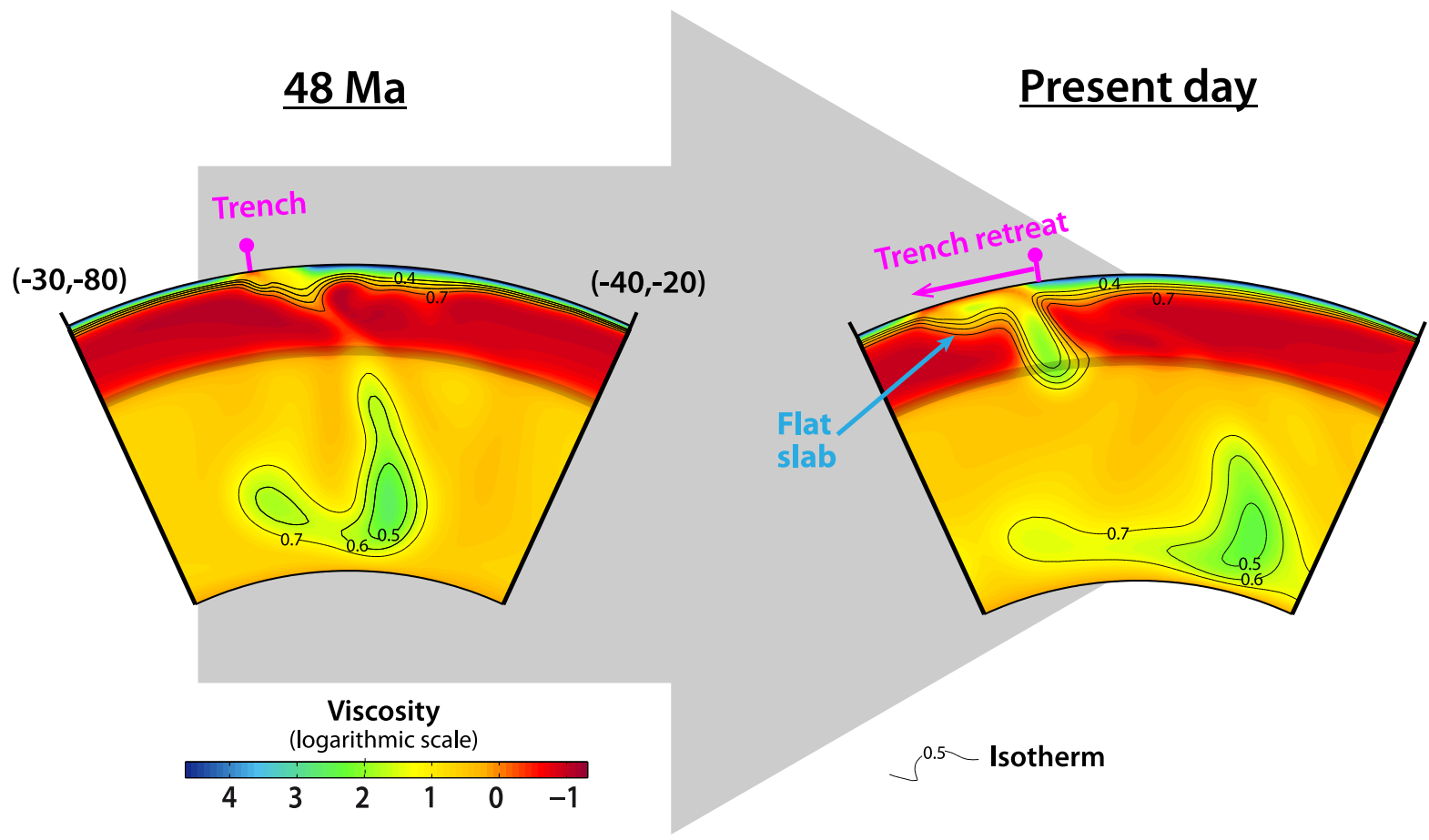

Figure 6: Cross sections beneath South America (location shown Fig 3) of the reconstructed viscosity fields in model $\mathrm{E}$, for $48 \mathrm{My}$ ago and present-day. The pink marker shows the location of the plate-boundary $48 \mathrm{My}$ age, and the pink arrow the motion of the plate boundary since that time. Isotherms 0.4 to 0.7 are shown.

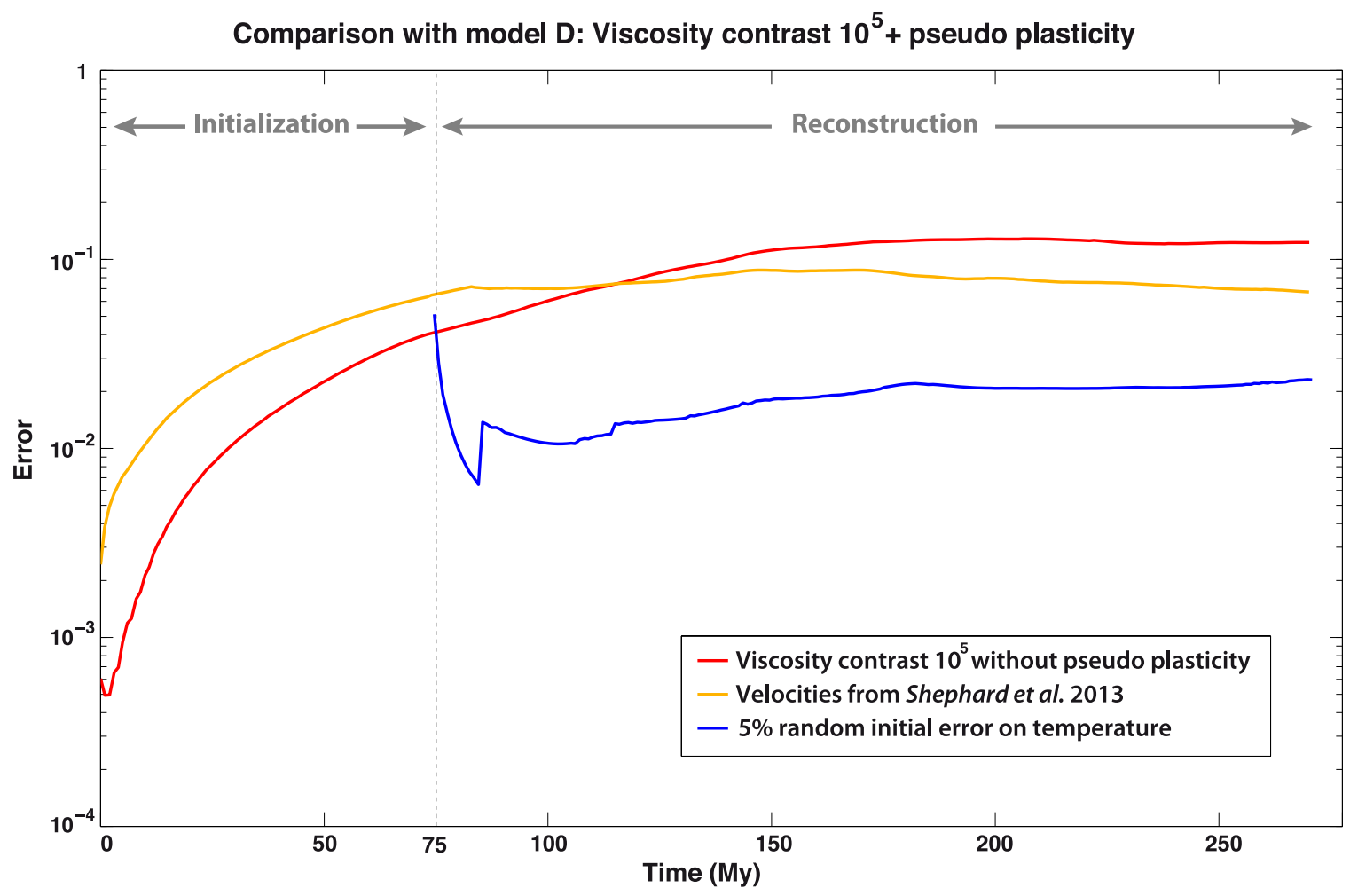

Figure 7: Evolution of error relative to model D, produced by ignoring pseudo-plasticity (model C), taking the plate reconstruction of Shephard et al. [2013], and perturbing initial conditions with a random noise producing a 5\% global error. 